\title{
A New Dynamic External Fixation Method in Finger Replantations and Toe-To-Hand Transfers
}

\section{Parmak Replantasyonları ve Ayaktan Ele Parmak Nakillerinde Yeni Bir Dinamik Eksternal Fiksasyon Yöntemi}

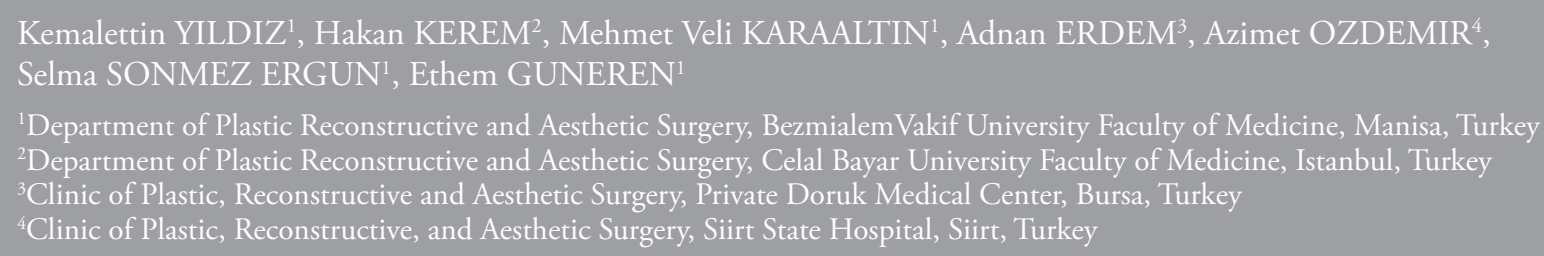

\section{ABSTRACT}

Objective: This study presents a simple and versatile finger fixation method facilitating rehabilitation in the early period and better functional results in replantation and toe-to-hand transfer patients.

Methods: In 12 patients, bone fixations were performed by using a dynamic external finger fixator system. The duration of fixations was recorded. The potential complications, such as non-union, pain, joint stiffness, infection of pins, inadequate stabilization, and swelling, were documented. Subjective pain scale was applied on each patient, and the level of satisfaction of patients was examined.

Results: All finger transfers and replantations were achieved. The mean time of bone fixation was 11.6 minutes ( 9 to $20 \mathrm{~min}$.). Nonunion associated with fixation and infection did not occur. Whereas 8 patients were satisfied with the functional results, 3 replantation cases and 1 toe-to-hand transfer patient were dissatisfied. In the assessment of the appearance of the finger, 2 replantation cases and 4 toe-to-hand transfer patients ( $50 \%$ of all cases) were dissatisfied.

Conclusion: We are convinced that this dynamic external fixation system, including versatile advantages, such as arranging earlier finger motion, having a simple and quick learning process, reducing the operation time, being able to be used as contributing material in anastomosis, and having fewer complications, can be successfully used in replantations and toe-to-hand transfers.

Key Words: Toe-to-hand transfer, replantation, dynamic external fixator, ligamentotaxis

\section{ÖZET}

Amaç: Bu çalışmada replantasyon ve ayaktan ele parmak nakil olgularında rehabilitasyonun erken dönemde yapılmasına ve daha iyi fonksiyonel sonuçlar alınabilmesine olanak sağlayan basit ve çok yönlü işlevsel bir parmak tespit yöntemini sunulmaktadır.

Yöntemler: Oniki hastada dinamik eksternal parmak tespit sistemi ile kemik fiksasyonu sağlandı. Kemik tespit süreleri kaydedildi. Ameliyat sonrası kemik tespite ilişkin kaynamama, ağrı, eklem sertlikleri, pin enfeksiyonu, yetersiz stabilizasyon ve şişlik gibi olası komplikasyonlar dokümante edildi. Hastalara subjektif ağrı değerlendirmeleri uygulandı ve memnuniyet düzeyleri sorgulandı.

Bulgular: Tüm parmak nakilleri ve replantasyonları başarı ile gerçekleştirildi. Kemik tespit süresi ortalama 11,6 dakika (dağılım 9-20 dakika) olarak saptandı. Tespite bağlı kırık segmentte kaynamama, enfeksiyon gerçekleşmedi. 8 hasta fonksiyonel sonuçtan memnun iken, 3 replantasyon olgusu ile 1 ayaktan ele parmak nakli olgusu memnuniyetsizlik belirtmiştir. Parmak görünümü için değerlendirmede ise 2 replantasyon olgusu ile 4 ayaktan ele parmak nakli olgusu (olguların \%50'si) memnuniyetsizlik bildirmiştir.

Sonuç: Dinamik eksternal fiksasyon sistemi parmak hareketlerine erken dönemde olanak sağlaması, kolay ve hızlı öğrenme süreci, ameliyat süresini azaltması, damar anastomozunda yardımcı materyal olarak kullanılabilmesi ve komplikasyonlarının azlığı gibi çok yönlü avantajları nedeniyle replantasyon ve ayaktan ele parmak nakli olgularında başarıyla kullanılabileceğini düşünmekteyiz.

Anahtar Sözcükler: Ayaktan ele parmak nakli, replantasyon, dinamik eksternal fiksatör, ligamentotaksis 


\section{Giriş}

Son yıllarda el cerrahisi alanında ayaktan ele parmak nakilleri geniş bir popularite ve kullanım alanı bulunmaktadır. Bununla birlikte parmak replantasyonları da dünya genelinde yaygın olarak başarıyla gerçekleştirilmektedir. Hasarlı parmaktaki eklem hareketini serbest bırakan çeşitli yeni fiksasyon teknikleri kullanıma sunulmuştur. Bu tekniklerle erken rehabilitasyon mümkün olmakta ve daha iyi fonksiyonel sonuçlar alınabilmektedir (1-4). Bu yazıda replantasyon ve ayaktan ele parmak nakil olgularında kullandığımız basit ve çok yönlü işlevsel bir parmak tespit yöntemini sunmaktayız.

\section{Yöntemler}

2010-2012 yılları arasında başvuran 5'i ayaktan ele parmak nakli, 7'si parmak replantasyonu olan toplam 12 hastada bu yöntem uygulanmıştır. Hastaların 9'u erkek, 3'ü kadın iken ortalama yaş 28,3 (19-41 yaş aralığı). Tüm hastalar genel anestezi altında ameliyat edildiler.

Replantasyonlar, distal interfalengeal eklem ( $\mathrm{n}: 3$ hasta) ve proksimal interfalengeal eklem ( $\mathrm{n}: 4$ hasta) seviyesinde gerçekleştirilmiştir. Replantasyon hastalarının takip döneminde nihai olarak ulaştıkları aktif fleksiyon dereceleri tespit edildi. (AREX, Ligamentotaxor ${ }^{\circ}$ Palaiseau, Fransa) parmak tespit sistemi ile kemik fiksasyonu sağlanırken eklem hareketlerine olanak verildi (Resim 1 ve 2). Bu tespit 6 hafta süreyle uyguland. Ameliyat sonrası 3. haftada rehabilitasyona ve parmak hareketlerine başlandı. Hastalar ortalama 9,3 ay (6-15 ay aralığı) süreyle takip edildi. Replantasyon ve ayaktan ele parmak nakli ameliyatlarındaki kemik tespit süreleri kaydedildi.

Ligamentotaxor sistemi, 3 adet pin, bir adet rod ile birlikte 2 adet plastik eklem ve 2 adet yaydan oluşan dinamik eksternak fiksasyon sistemidir. Sistem perkütan yolla ve eklem yüzeyine hasar vermeden uygulanmaktadır (5).

Hastalarda ameliyat sonrası kemik tespite ilişkin kaynamama, ağrı, eklem sertlikleri, pin enfeksiyonu, yetersiz stabilizasyon, sekonder artroz, şişlik gibi olası komplikasyonlar dokümante edildi.

Hastaların ameliyat sonrası 3. ayda subjektif ağrı değerlendirmeleri $10 \mathrm{~cm}$ 'lik görsel analog skalası (GAS) ile gerçekleştirildi ve ameliyat sonrası 6 . ayda memnuniyet düzeyleri sorgulandı.

\section{Bulgular}

Tüm parmak nakilleri ve replantasyonları başarı ile gerçekleştirildi. Nekroz veya kısmi parmak kaybı oluşmadı. Kemik tespit süresi ortalama 11,6 dakika (dağılım 9-20 dakika) olarak saptand. Ayrıca bu tespit sistemi damar anastomozlarında dikiş iplerinin askısı olarak da kullanıldı.Böylece anastomozlar kolay ve hızlı bir şekilde gerçekleştirildi. Bu sonuç ligamentotaxor sisteminin ek bir avantajı olarak değerlendirildi.

Replantasyon olgularında tüm hastalarda çekilen grafilerinde kaynama saptand. Ligamentotaxor ${ }^{\circ}$ (AREX,Palaiseau,

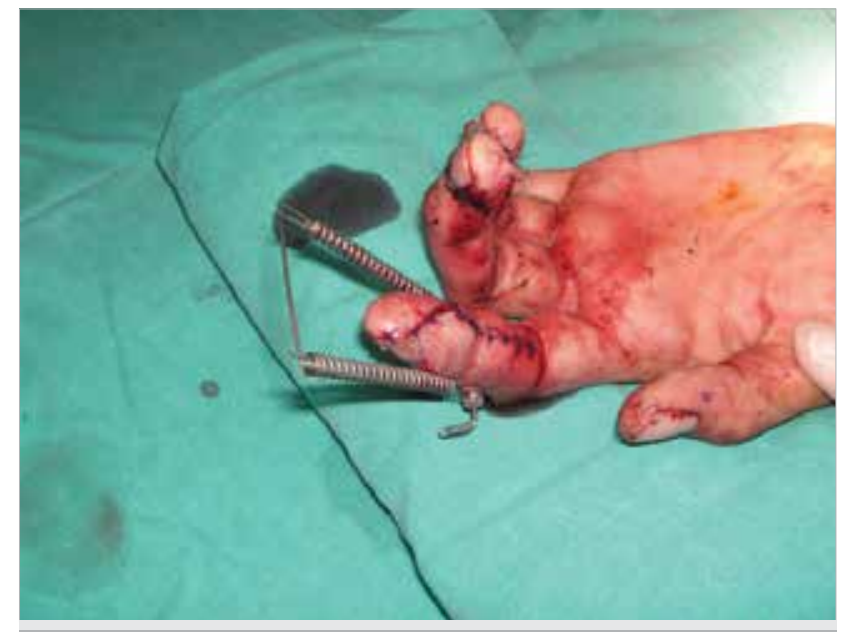

Resim 1. Dinamik eksternal fiksasyon sisteminin bir replantasyon olgusunda kullanımı

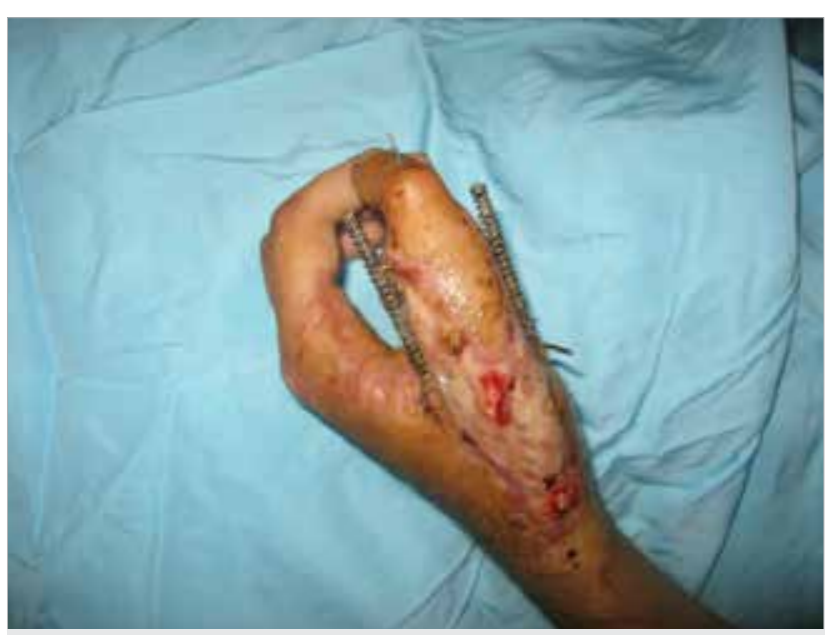

Resim 2. Dinamik eksternal fiksasyon sisteminin ayaktan ele parmak nakli olgusunda kullanımı

Fransa) sistemi ile tespite bağlı kırık segmentte kaynamama, enfeksiyon gerçekleşmedi. Parmaklarda angülasyon veya deformite oluşmad. Distal interfalengeal seviyesinde replante edilen parmakların (n:3) ortalama aktif fleksiyon derecesi 28 (n (1) 25 derece, n (2) ve n (3) 30 derece) iken proksimal falanks seviyesi replantasyonlarda (n:4) ortalama aktif fleksiyon 52 derece (dağılım 40-60 derece) olarak saptandı.

GAS değerlendirmesinde replantasyon olgularınnın ortalaması 3,2 (dağılım 2,4-3,8), ayaktan ele parmak nakli hastaların ortalaması 3,7 (dağılım 2,8-4,2) idi. Ayaktan ele parmak nakli gerçekleştirilen iki hastada ameliyat sonrası ağrı yakınması mevcuttu ve opioid türevi ilaç tedavisi uygulanırken diğer hastalar rutin analjezik uygulaması (steroid olmayan anti-inflamatuar ve parasetamol türevi) ile ağrı yakınmaları oluşmadan tedavi edildiler. Ameliyat sonrası erken dönemde (ilk 3 hafta) şişlik, replantasyon ve parmak nakli hastalarında mevcut iken geç dönemde hastalarda kalııı şişlik saptanmadı (Resim 3).

Tespit sistemi kullanılırken (3. haftada) eklem hareketlerine izin verildi. Ameliyat sonrası takiplerinde hastalarda eklem 


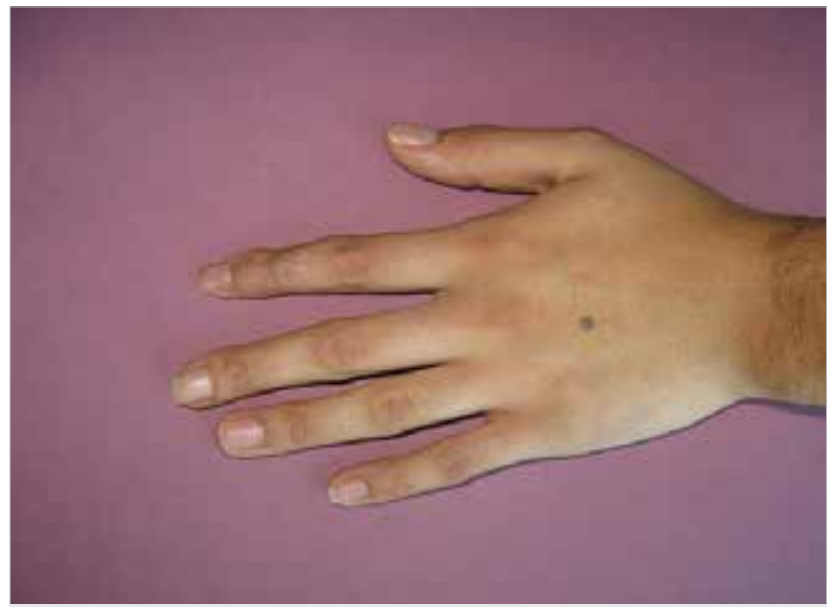

Resim 3. Replantasyon olgusunun geç dönem görüntüsü

sertliği ile tendon yapışıklıkları tespit edilmedi. Hasta memnuniyeti değerlendirmesinde 8 hasta fonksiyonel sonuçtan memnun iken 3 replantasyon olgusu ile 1 ayaktan ele parmak nakli olgusu iş hayatında ve gündelik yaşamında kısıtlılık tarif ederek memnuniyetsizlik belirtmiştir. Parmak görünümü için değerlendirmede ise 2 replantasyon olgusu ile 4 ayaktan ele parmak nakli olgusu toplam 6 hasta (olguların \%50'si) memnuniyetsizlik bildirmiştir.

\section{Tartı̧̧ma}

Parmak kırıklarında konvansiyonel olarak Kirschner teli veya vida ile fiksasyon yöntemleri kullanılmaktadır. Bu yöntemlerin tendon yapışıklığı, kapsül veya ligamanlarda fibrozis oluşturması, kırık parçada avasküler nekroz oluşturması gibi komplikasyonları mevcuttur $(6,7)$. Ayrıca eklem yüzeyinden geçen K-teli fiksasyonları eklem yüzeyinde hasar oluşturmakta ve erken hareketlendirmeye engel teşkil etmektedir. Bu nedenle erken mobilizasyona olanak veren ve eklem sertliğinin gelişmesini önleyen dinamik eksternal fiksasyon yöntemleri geliştirilmiştir. Ligamentotaksis prensipleri doğrultusunda eklem kapsül ve ligaman yapılarına uygulanan dinamik distraksiyon ile kırık ve kemik tespiti gerçekleştirilebilmektedir $(6,8-10)$.

Ligamentotaxor (AREX,Palaiseau, Fransa) sistemi diğer dinamik eksternal fiksayon sistemleri gibi erken eklem hareketini sağlamakta ve tendon yapışıklıkları ile eklem sertliklerini engellediği gösterilmiştir $(2,5,11)$. Bu sistemin bir diğer avantajı öğrenme eğrisinin kısalığı, kullanım kolaylığı ve ağır olmaması sayılabilir (5). Pin enfeksiyonu ve osteoliz bazı dinamik eksternal sistemlerde gösterilmiştir (12-14). Olgularımızda ise bu komplikasyonlar gelişmemiştir. Osteolizin olmamasının mekanik stresin pinlerden ziyade plastik eklemlerde olmasına bağlı olabileceği bildirilmiştir (5). Suzuki ve ark.nın tariflediği dinamik eksternal fiksasyon sistemi basit ve ucuz olmakla birlikte sisteme pozisyon verme ve ayarlama yapma konularında yetersiz kalabildiği ve sonuçların cerrahın yete-
Uyguladığımız fiksasyon yöntemi ile erken eklem hareketi sağlandı ve buna bağlı olarak olgularda fonksiyonel sonuçlar elde edildi. Bu sonucun elde edilmesinde komplikasyonların diğer konvansiyonel yöntemlere oranla az olmasının rolü olduğunu düşünmekteyiz. Hastalarda ağrı yakınması sadece 2 olguda gerçekleşmiştir. Bu yakınmanın az olması da bu kemik tespit sisteminin fonksiyonel bir avantajı sayılabilir. Ağrı yakınmasının belirgin olduğu bu iki hasta ayaktan ele nakil olgusudur ve donör saha morbiditesinin de bu sonuçlarda etkili olabileceğini düşünmekteyiz.

Parmak görünümündeki memnuniyetsizlik oranının yüksekliği (özellikle ayaktan ele parmak nakli olgularında) hasta beklentilerinin yüksek olması, olguların nakledilen parmakları eski parmaklarıyla özdeşleştirmek beklentilerine bağlı olabilir. $\mathrm{Bu}$ nedenle olgular psikososyal yönden parmaklarını benimseyecekleri sürenin sonrasında geç dönem takiplerinde tekrar değerlendirilebilir. Hastalarda tanımlanmış bir görsel memnuniyet skalası uygulanmamasıyla birlikte fonksiyonel açıdan memnun olmayan 4 hastanın 3 tanesi proksimal falanks seviyesinde yapılan replantasyon olguları idi. Bu sonuç, bu seviyedeki replantasyonlarda işlevsel kazancın ve aktif hareket açıklığının az olmasına bağlı olabileceğini düşündürmektedir.

\section{Sonuç}

Parmak hareketlerine ve rehabilitasyonuna erken dönemde olanak sağlaması, kolay ve hızlı öğrenme süreci, ameliyat süresini azaltması ve damar anastomozunda yardımcı materyal olarak kullanılabilmesi, komplikasyonlarının azlığı gibi çok yönlü avantajları olan bu dinamik eksternal fiksasyon sisteminin replantasyon ve ayaktan ele parmak nakli olgularında başarıyla kullanılabileceğini düşünmekteyiz.

Ethics Committee Approval: Ethics committee approval was not received due to the retrospective nature of the study.

Informed Consent: Written informed consent was obtained from the patients who participated in this study.

Peer-review: Externally peer-reviewed.

Author Contributions: Concept - K.Y., M.V.K., H.K.; Design - M.V.K., K.Y.; Supervision - E.G., H.K.; Funding - A.E., A.Ö.; Materials - A.E., A.Ö.; Data Collection and/or Processing - K.Y., M.V.K, A.Ö.; Analysis and/or Interpretation - K.Y., M.V.K.; Literature Review - K.Y.; Writing - K.Y.; Critical Review - S.S.E., E.G.

Conflict of Interest: No conflict of interest was declared by the authors.

Financial Disclosure: The authors declared that this study has received no financial support.

Etik Komite Onayı: Çalışmanın retrospektif tasarımından dolayı etik komite onayı alınmamıştır.

Hasta Onamı: Yazılı hasta onamı bu çalışmaya katılan hastalardan alınmıştır.

Hakem değerlendirmesi: Dış bağımsız. 
Yazar Katkıları: Fikir - K.Y., M.V.K., H.K.; Tasarım - M.V.K., K.Y.; Denetleme - E.G., H.K.; Kaynaklar - A.E., A.Ö.; Malzemeler - A.E., A.Ö.; Veri Toplanması ve/veya İşlemesi - K.Y., M.V.K, A.Ö.; Analiz ve/veya Yorum K.Y., M.V.K.; Literatür Taraması - K.Y.; Yazıyı Yazan - K.Y.; Eleştirel İnceleme - S.S.E., E.G.X.X.

Çıkar Çatışması: Yazarlar çıkar çatışması bildirmemişlerdir.

Finansal Destek: Yazarlar bu çalışma için finansal destek almadıklarını beyan etmişlerdir.

\section{Kaynaklar}

1. Agee JM. Unstable fracture dislocations of the proximal interphalangeal joint of the fingers. A preliminary report of a new treatment technique. J Hand Surg Am 1978; 3: 386-9. [CrossRef]

2. Allison DM. Fractures of the base of the middle phalanx treated by dynamic external fixation device. J Hand Surg Br 1996; 21: 305-10. [CrossRef]

3. Inanami H, Nimomiya S, Okutsu I, Tarui T. Dynamic external fixation for fracture dislocation of the proximal interphalangeal joint. J Hand Surg Am 1993; 18: 160-4. [CrossRef]

4. Suzuki Y, Matsunaga T, Sato S, Yokoi T. The pins and rubbers traction system for treatment of comminuted intraarticular fractures and fracture-dislocations in the hand. J Hand Surg Br 1994; 19: 98-107. [CrossRef]

5. Körting O, Facca S, Diaconu M, Liverneaux P. Treatment of complex proximal interphalangeal joint fractures using a new dynamic external fixator: 15 cases. Chir Main 2009; 28: 153-7. [CrossRef]

6. Bhamra JS, Khan WS, Pastides P. The use of the s-quattro dynamic external fixator for the treatment of intr-articular phalangeal fractures: a review of the literature. Open Orthop J 2012; 6: 54-9. [CrossRef]
7. Khan W, Fahmy N. The s-quattro in the management of acute intraarticular phalangeal fracture of the hand. J Hand Surg Br 2006; 31: 79-92. [CrossRef]

8. Mullett JH, Synnott K, Nöel J, Kelly EP. Use of the 's' quattro dynamic external fixator in the treatment of difficult hand fractures. J Hand Surg Br 1999; 24: 350-4. [CrossRef]

9. Bostock S, Nee P, Fahmy NR, The 's' Quattro results of the treatment in 11 cases of sports injury. Br J Sports Med 1993; 27: 268-70. [CrossRef]

10. Keramidas E, Solomos M, Page RE, Miller G. The suzuki frame for complex intra-articular fractures of the proximal interphalangeal joint of the fingers. Ann Plast Surg 2007; 58: 484-8. [CrossRef]

11. Salter RB, Simmonds DF, Malcolm BW, Rumble EJ, MacMichael D, Clements ND. The biological effect of continous passive motion on the healing of full-thickness defects in articular cartilage: an experimental investigation in the rabbit. J Bone Joint Surg Am 1980; 62: 1232-51.

12. Hynes MC, Giddins GE. Dynamic external fixation for pilon fractures of interphalangeal joints. J Hand Surg Br 2001; 26: 122-4. [CrossRef]

13. Bain GI, Mehta JA, Heptinstall RJ, Bria M. Dynamic external fixation for injuries of the proximal interphalangeal joint. J Bone Joint Surg Br 1998; 80: 1014-9. [CrossRef]

14. Kneser U, Goldberg E, Polykandriotis E, Loos B, Unglaub F, Bach A, et al. Biomechanical and functional analysis of the pins and rubbers traction system for treatment of proximal interphalangeal joint fracture dislocations. Arch Orthop Trauma Surg 2009; 129: 29-37. [CrossRef]

15. Damert HG, Altman S, Kraus A, Infanger M, Sattler D. Treatment of intraarticular middle phalanx fractures using the Ligamentotaxor ${ }^{\circledR}$. Hand 2013; 8: 460-3. [CrossRef] 